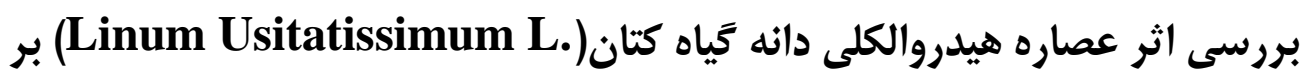

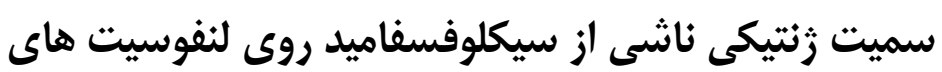 \\ خون محيطى انسان
}

محمد شكرزاده'، عباس محمديور'، مونا مدانلو'، نركس كاركر دارابى'، فائزه خواجوى ب*

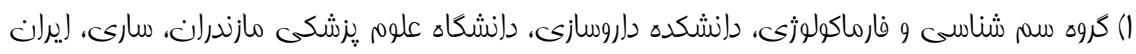

N) كروه زثتيك، دانشكاه غير(تتفاعى سنا مازندرلن، سارى، إيران

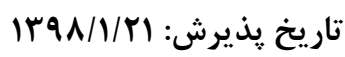

تاريخ دريافت:

\begin{abstract}
جکكيده

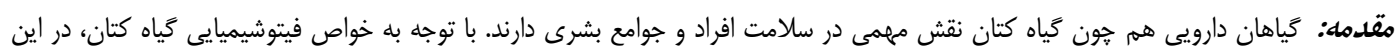

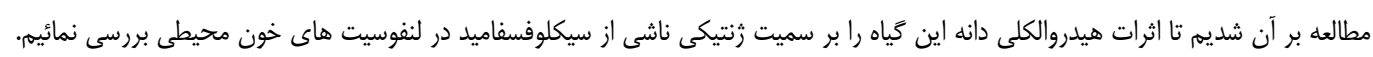

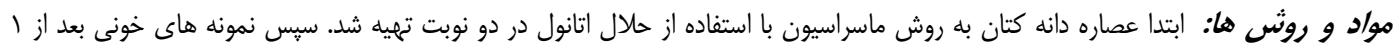

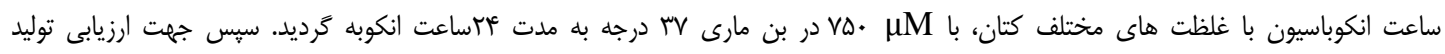

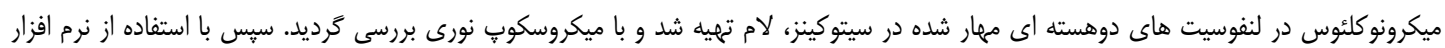

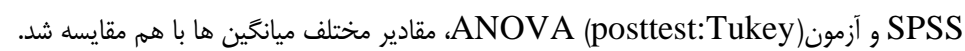

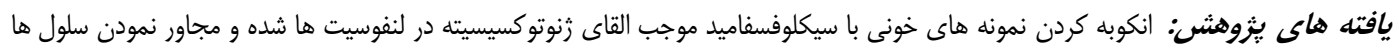

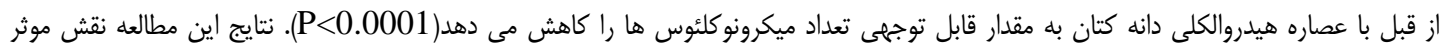

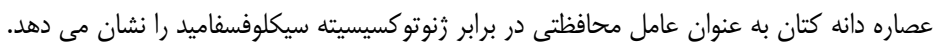

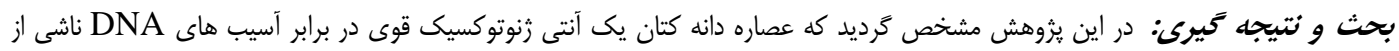

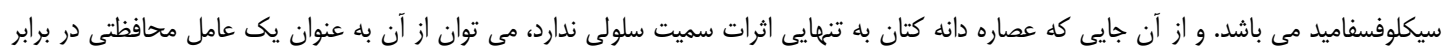
اثرات سمى سيكلوفسفاميد استفاده كرد.
\end{abstract}

$$
\text { وازه هاى كليدى: زنوتاكسيسيته، سيكلوفسفاميد، دانه گياه كتان، لنفوسيت انسانى }
$$

Email: faezekhajavi1370@gmail.com

Copyright () 2019 Journal of Ilam University of Medical Science. This is an open-access article distributed under the terms of the Creative Commons Attribution international 4.0 International License (https://creativecommons.org/licenses/by-nc/4.0/) which permits copy and redistribute the material, in any medium or format, provided the original work is properly cited. 


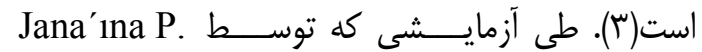
Moraes بررسى اثر محافظتى جنتيسيك اسيد در برابر سميت دوان

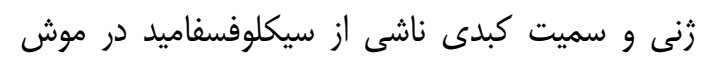
نزاد Swiss يرداختند. موش ها توسط جنيت أنتيسيك اسيد

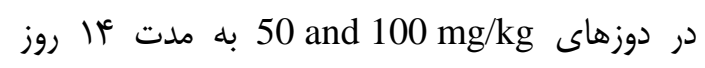

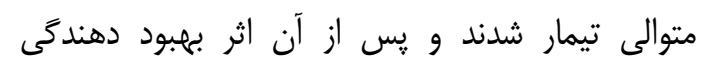

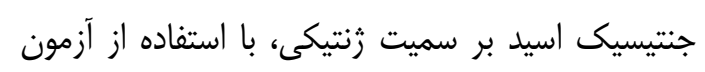

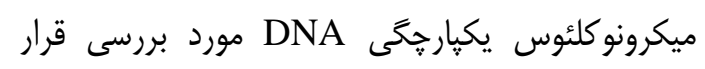
كرفت و فعاليت آنزيم هاى مختلف يكارئ اكسيداتيو در بافت

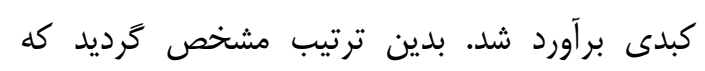
فعاليت آنزيم هاى آنتى اكسيدان بازسازى شلى شده و و

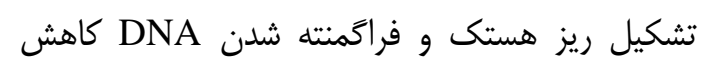

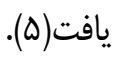

كَياهان دارويى نقش مهمى در سلامت افراد و

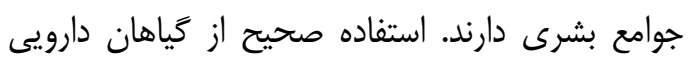

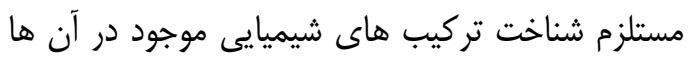

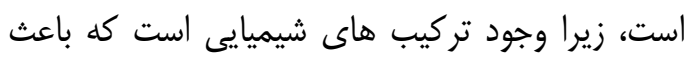

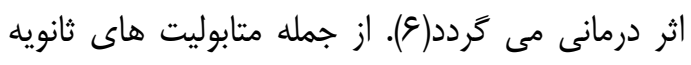

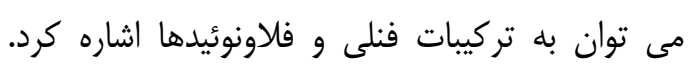

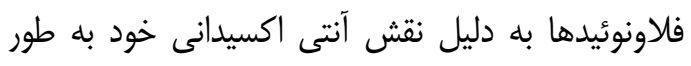

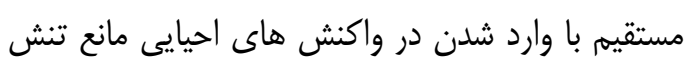

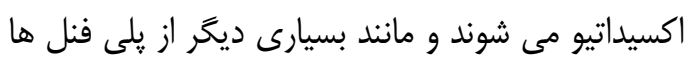
جمع كننده راديكال هاى آزاد هستند زيرا به به عنوان كروه هاى قوى الكترون دهنده ويروتون دهنده عمل

$$
\text { مى كنند(V-q). }
$$

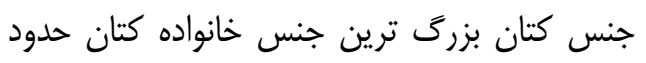

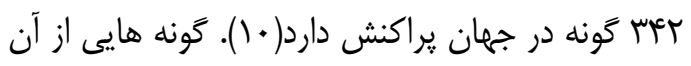
بوته اى هستند و در نواحى گرمسيرى يافت مى شود شود دارد

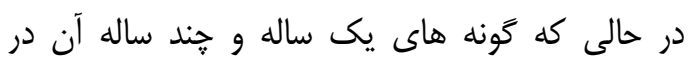
نواحى معتدل جهان يافت مى شود(1).

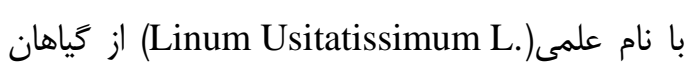

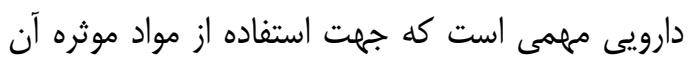

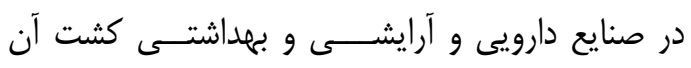

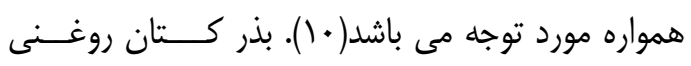

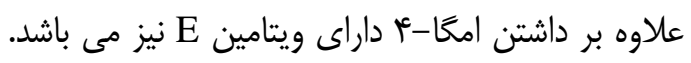
خاصيت مهم ديخر روغن كتان اثر ضد تورم و برطرف

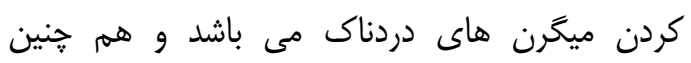

مقدمه

تركيبات شيميايى و عوامل محيطى زيادى وجود

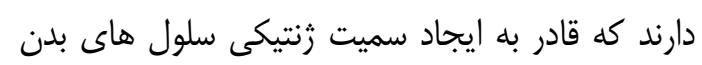

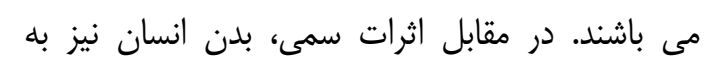

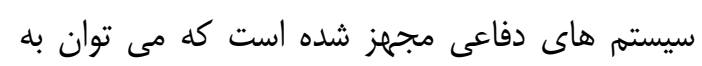

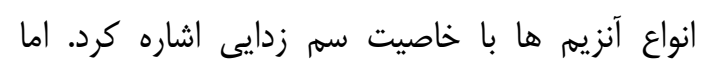

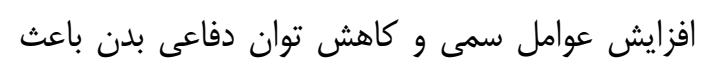

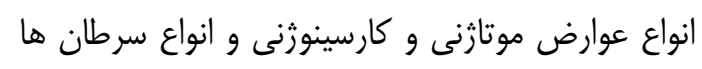

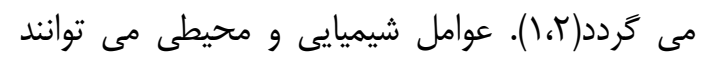

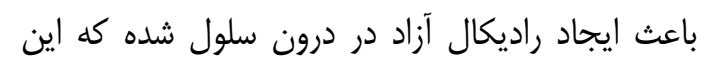

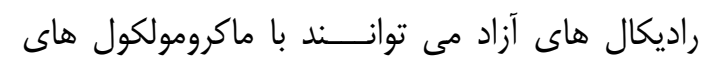

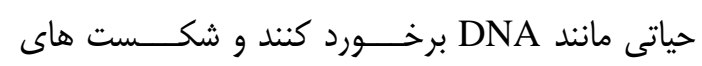
كروموزومى ايجاد كنند و منجر به آسيب زئن آنتيكى شوند

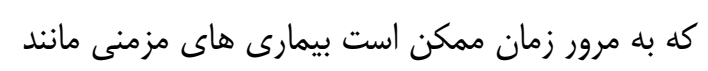
سرطان ايجاد كنند(ז).

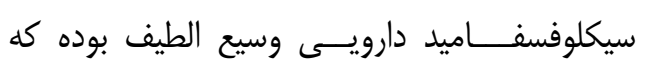

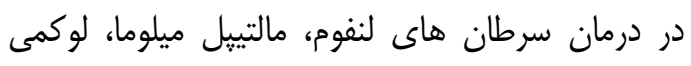

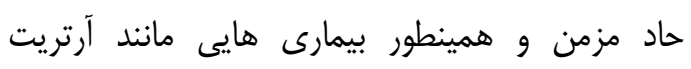

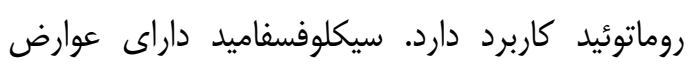

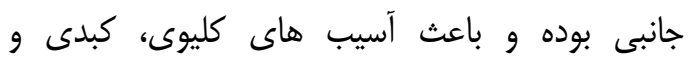

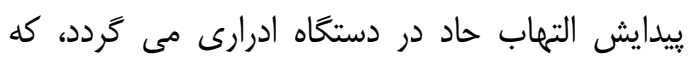

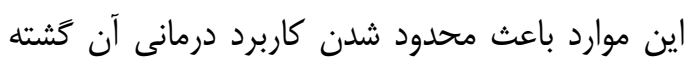

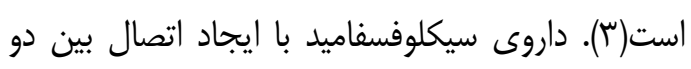

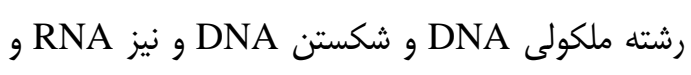
هم جنين مهار سنتز يروتئين اثر سلول كشى خود رأ رأ اعمال مى كند. اين داروى آلكيله كننده مولكول ها،

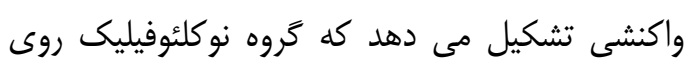

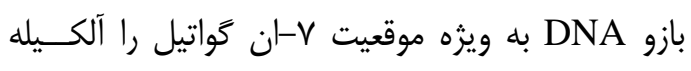
مى كند، اين مسئله سبب ايجاد بيوندهاى جانبى ميان مان

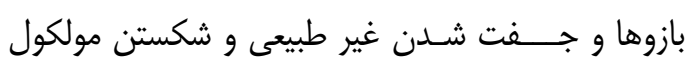

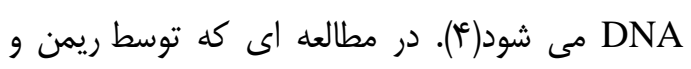

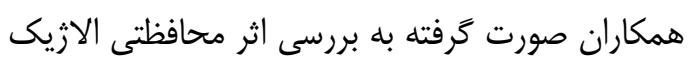

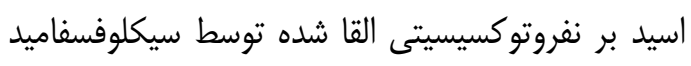

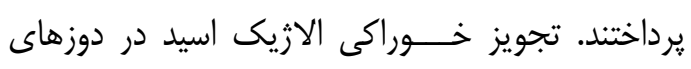

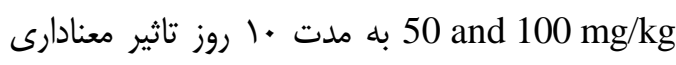

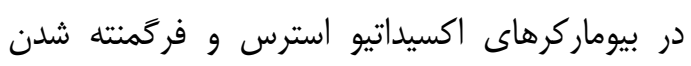
و ذخيره سازى انزيم هاى آنتى اكسيدانت مانند

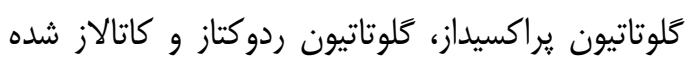


مخلوط حاصل به مدت ^^ ساعت بر روى شيكر با

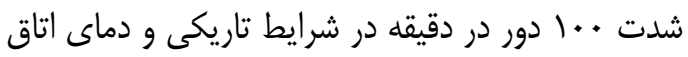

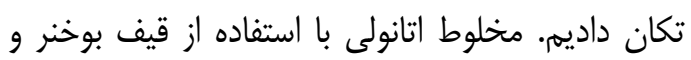

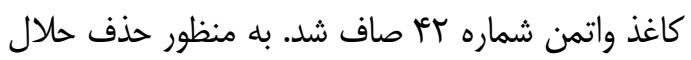
و تغليظ عصاره اتانولى از دستخاه تقطير در خلا خرخ خرخان

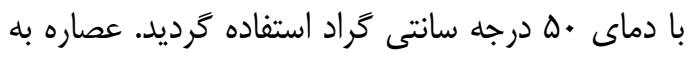

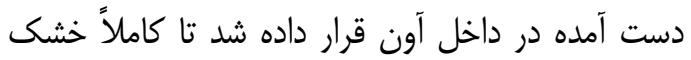

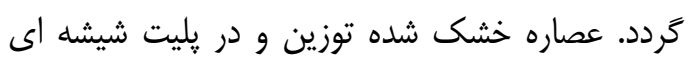

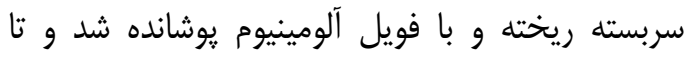
زمان انجام مراحل بعدى تحت شرايط مناسب نكخهدارى

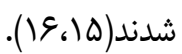

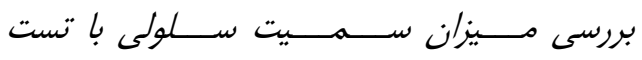
ميكرونوكلئوس: در اين مطالعه تجربى يس إز از دريافت لـان

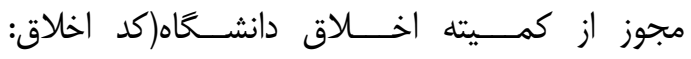

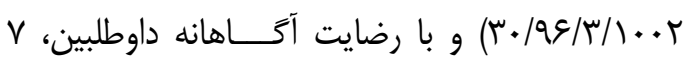
سى سى خون از سه داوطلب سالم و غير سيخارى كه

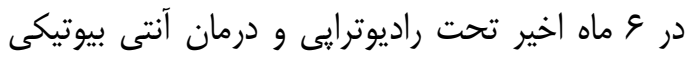

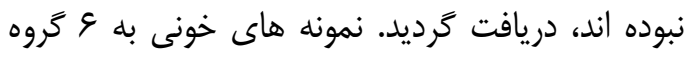

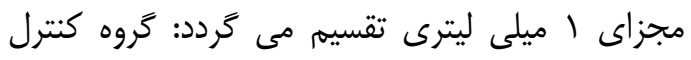

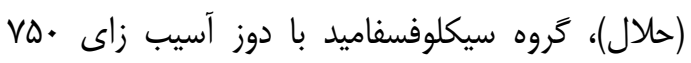

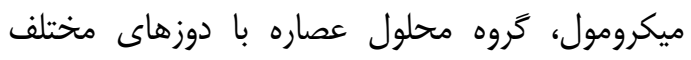

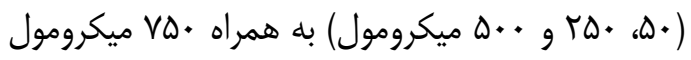

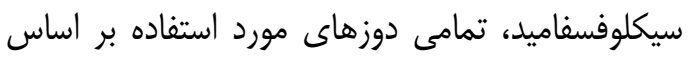

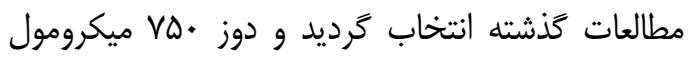
سيكلوفسفاميد بهترين و إيتيموم دوز ايجاد كننده سميت زنتيكى در in vitro مى باشد(IV) إنيموم دوزيل

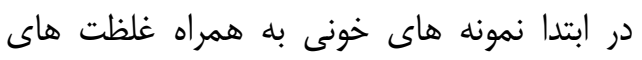

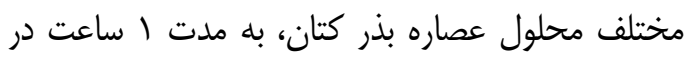

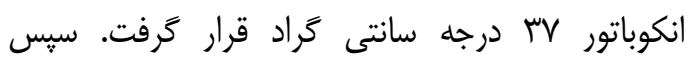

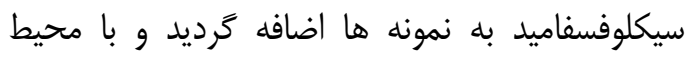

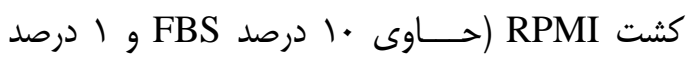

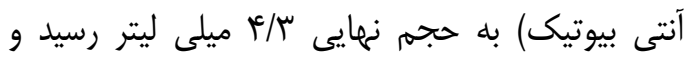

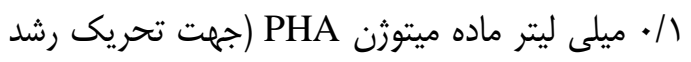

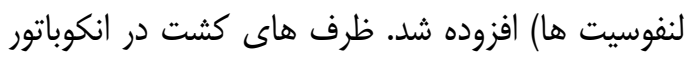

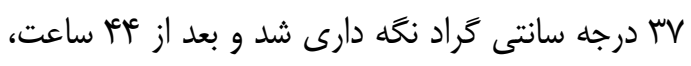

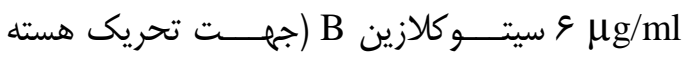
لنفوسيت ها به تقــــيم شدن بلدون تقسيم سلول) به اله

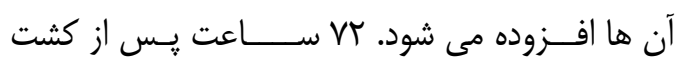

مصونيت بدن را در مقابل بيمارى ها بالا مى برد(I (I). كياه كتان حاوى مقادير بالايى تركيبات ليخنانى مانند

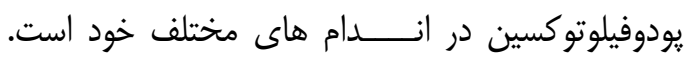

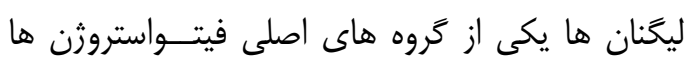

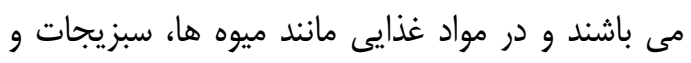
دانه هاى روغنى به ويزه دانه كتان يافت مي مي شود.

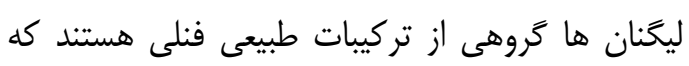

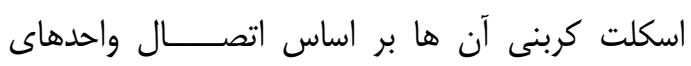

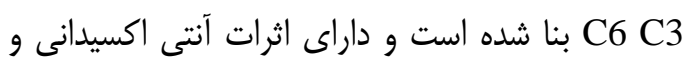

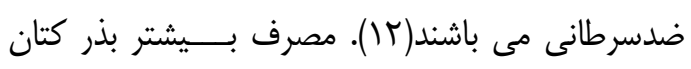

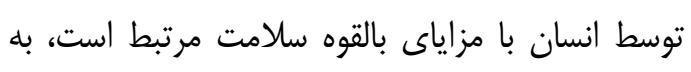
ويزه باعث ييشگيرى از CVD، هايير كلسترومى، علائم

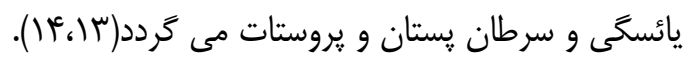

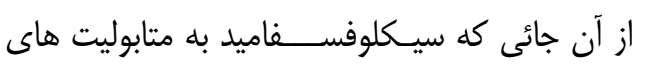

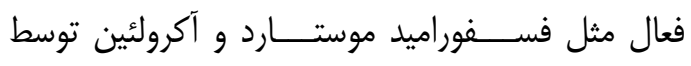
سيتوكروم ميكروزومال كبدى به همراه سيسته اكسيداز تبديل مى شود و اثر ضد نئويلاستيك سيكلوفسفاميد ناشى از فعاليت فسفوراميد موستارد بوده و آكرولئين

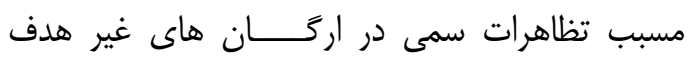
مى باشد و از سوى ديخر اين خياه با توجه به تركيبات موجود مثل تركيبات ويلى فنلى و تريينوئيدها مى تواند

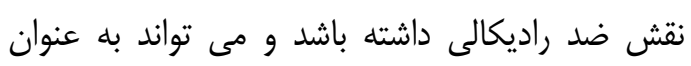
جلوگيرى كننده از اثرات سمى داروى مورد نظر مطرح

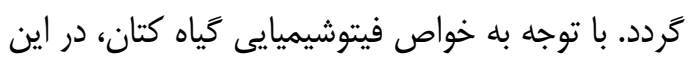
مطالعه بر آن شديم تا اثرات هيدروالكلى دانه اين خياه

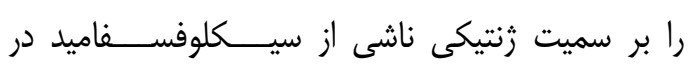
لنفوسيت هاى خون محيطى بررسى نمائيم.

مواد و روش ها

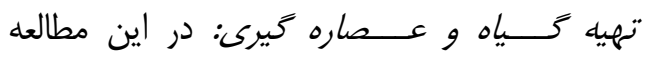

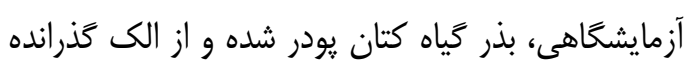

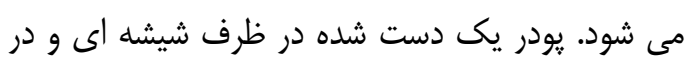
جاى خنــى جهت عصاره گيرى و انجام آزمايشات

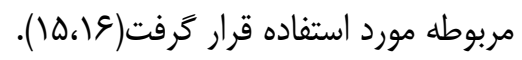
عصاره بذر كتان به روش ماسراسيون با استفاده از

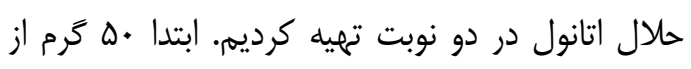
يودر بذر گياه الى شده با ترازوى ديجيتال توزين شد.

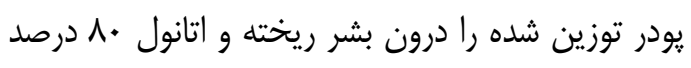
به آن اضافه كرديم تا سطح يودر را كاملاً بيوشاند. 
و تا زمانى كه محلول رويى سلول ها شفاف و بيرنت نمايد، ادامه يافت و در آخرين مرحله يس إنه از سانتريفوز،

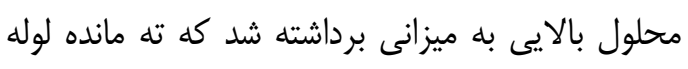
سانتريفوز فقط ه/ • ميلى ليتر باشد(IV).

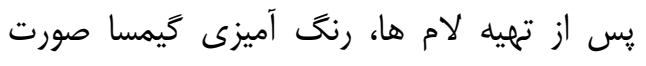

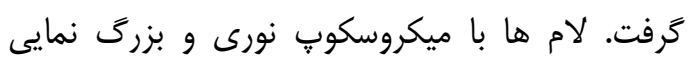

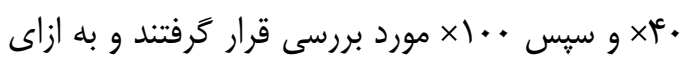

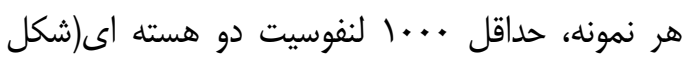

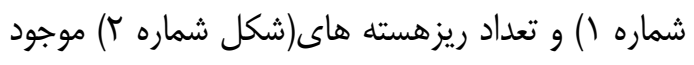

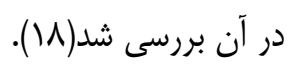

لنفوسيت ها، محصول بردارى صورت گرفت(IV).

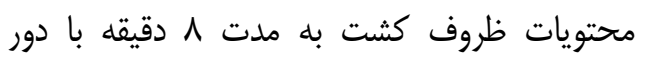

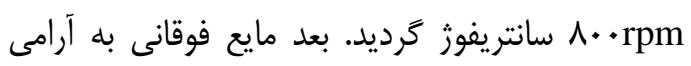

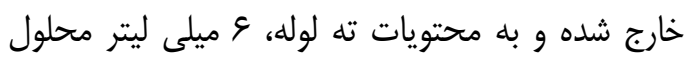

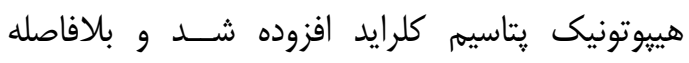

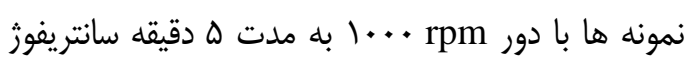

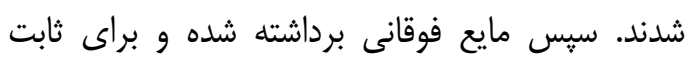
كردن سلول ها، محلول ثابت كننده شامل يكى قسمت بـاني

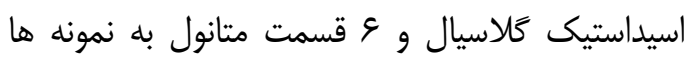
سانتريفوز شد و اين عمل به صورت ييايى(حداقل سّ بار)

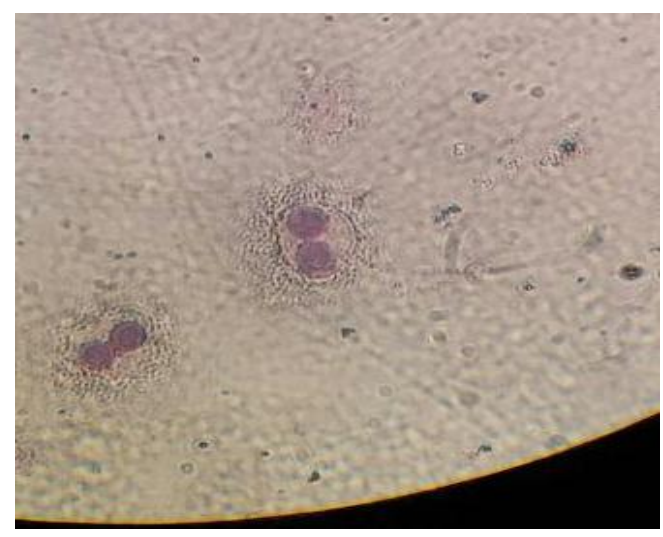

شكل شماره (.يك سلول دوهسته اى ساله(بدون ريز هسته)

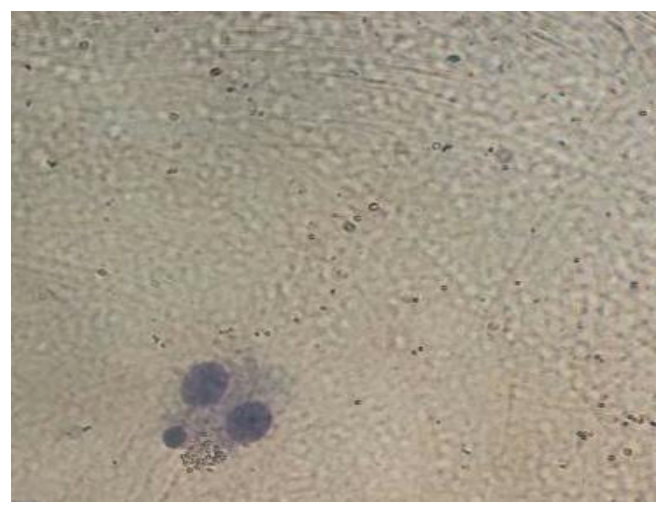

شكل شماره r. سلول دو هسته اى آسيب ديده(داراى ريز هسته)

نرم افزار Excell استفاده مى شود. P<0.05 معنى دار در نظر كرفته شد.

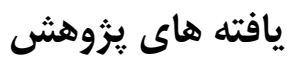

آزمايشات ما نشان داد كه عصاره هاره هيدروالكلى بذر

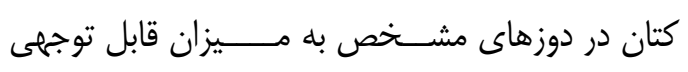

در اين مطالعه ابــتـدا اطلاعــــات به دست آمده از نمونه ها، دسته بندى مى كردد و يس از تعيين ميانكَين

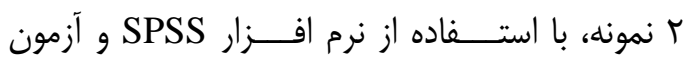
ANOVA (Post Test: Tukey) ميانكَين ها با هم مقايسه شده و براى رسم نمودارها از مقادير 
و كمترين ميزان ميكرونوكلئوس مربوط به گروه كنترل

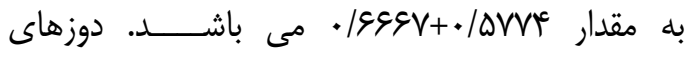

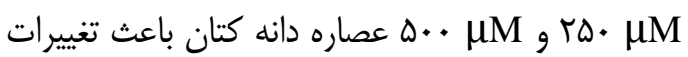
قابل ملاحظه اي در تعداد هسته هاى ميكرونوكلئوس در مقايسه با نمونه بدون عصاره دانه كتان شده است.

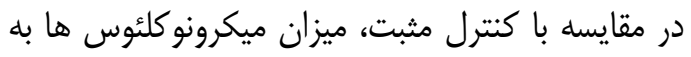

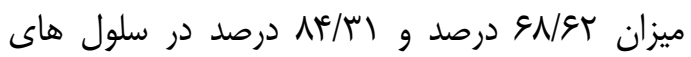

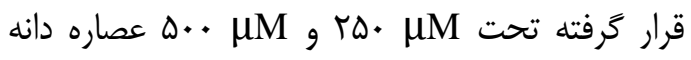

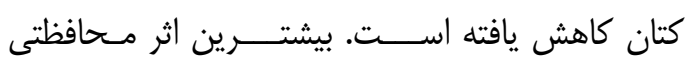

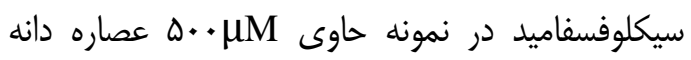

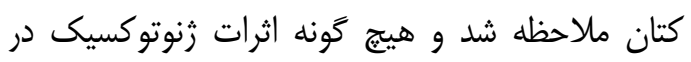

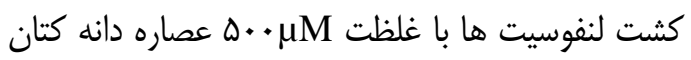

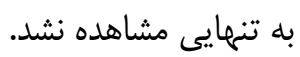

مى تواند آسيب زنتيكى ناشى از داروى سيكلوفسفاميد

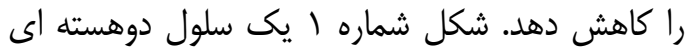

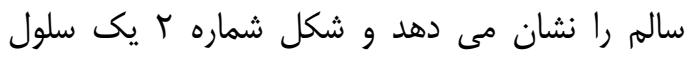
دوهسته اى داراى ميكرونوكلئوس(ريزهسته) را نشان

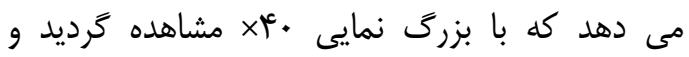
سبس از آن عكس بردارى شد. جدول شماره ا تعداد ميكرونوكلئوس هاى ايجاد

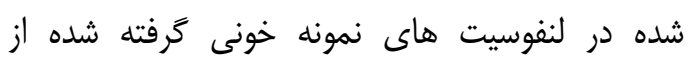

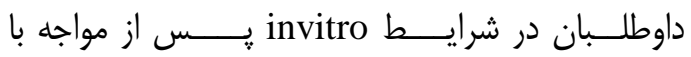
سيكلوفسفاميد و اثر محافظتى عصاره هيدروالكلى دانه

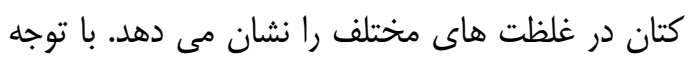

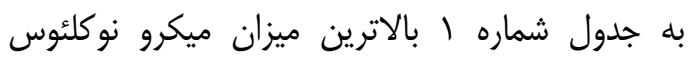

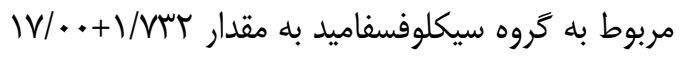

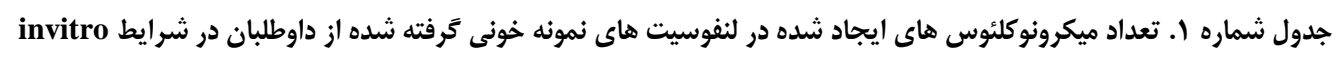

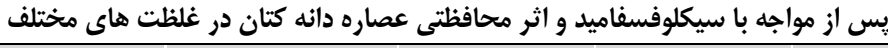

\begin{tabular}{|c|c|c|c|c|c|c|}
\hline كنترل & 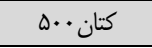 & سيكلو+كتان .•ه & سيكلو+كتان •ro & سيكلو+كتان •ه & سيكلوفسفاميد & كروه \\
\hline 1 & • & $r$ & r & 10 & 11 & 1 \\
\hline 1 & r & r & c & r & $M$ & r \\
\hline$\cdot$ & 1 & r & $\wedge$ & ir & 10 & $r$ \\
\hline$\cdot / \Delta W Y^{c+}+1999 V$ & س & $\cdot / \Delta V V^{c}+r / 9 q V$ & $r / \mu \cdot q+\Delta / \mu r \mu$ & س & $V / V Y r+I V / .$. & Mean+SD \\
\hline
\end{tabular}

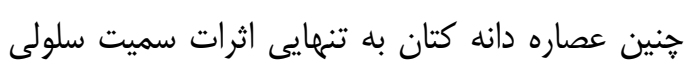

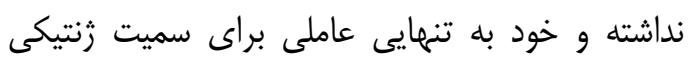

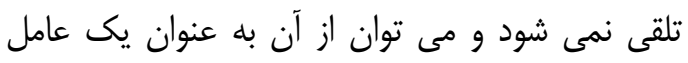
محافظتى در برابر اثرات سمى سيكلوفسفاميد استفاده

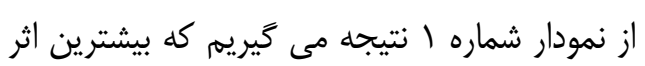

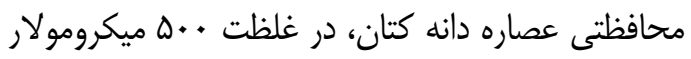

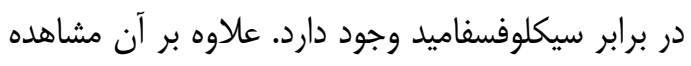
مى شود با افزايش غلظت عصاره دانه كتان اثرات محافظتى آن در برابر سيكلوفسفاميد بيشتر شد. هم أنمان

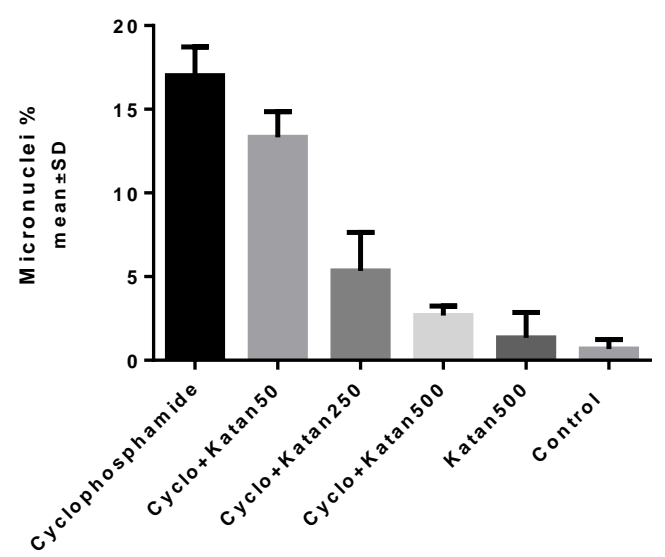

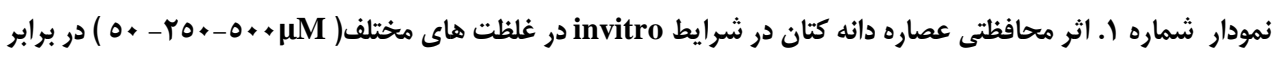

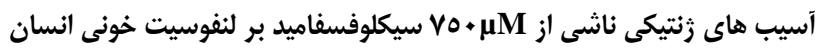


r مشاهده مى شود تفاوت معنادارى(P<0.0001) بين

نمونه كنترل در مقايسه با نمونه خونى مواجه شده با

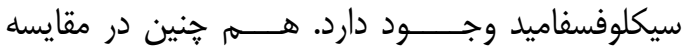

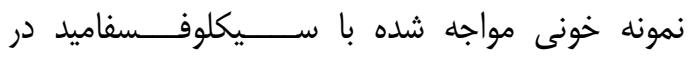

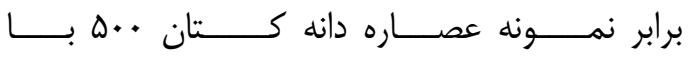

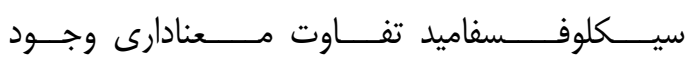

دارد
داده ها در جدول شماره r نشان مى دهد كه درصد

ميكرونو كلئوس لنفوسيت هايى كه تحت سيكلوفسفاميد

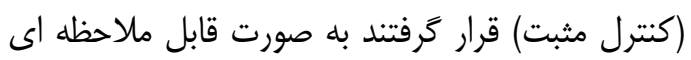

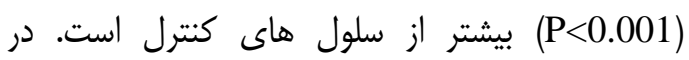

جدول بالا گروه هاى دريافت كننده دوزهاى مختلف آن

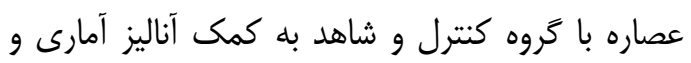

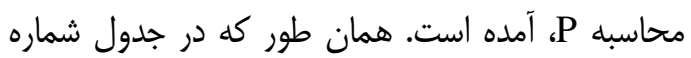

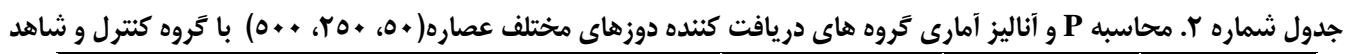

\begin{tabular}{lccc}
\hline \multicolumn{1}{c}{ Tukey's multiple comparisons test } & Significant? & Summary & P \\
\hline Cyclophosphamide vs. Cyclo+Katan50 & No & $\mathrm{ns}$ & 0.0942 \\
Cyclophosphamide vs. Cyclo+Katan250 & Yes & $* * * *$ & $<0.0001$ \\
Cyclophosphamide vs. Cyclo+Katan500 & Yes & $* * * *$ & $<0.0001$ \\
Cyclophosphamide vs. Katan500 & Yes & $* * * *$ & $<0.0001$ \\
Cyclophosphamide vs. Control & Yes & $* * * *$ & $<0.0001$ \\
Cyclo+Katan50 vs. Control & Yes & $* * * *$ & $<0.0001$ \\
Cyclo+Katan250 vs. Control & Yes & $*$ & 0.0243 \\
Cyclo+Katan500 vs. Control & No & $\mathrm{ns}$ & 0.6002 \\
Katan500 vs. Control & No & $\mathrm{ns}$ & 0.9931 \\
\hline
\end{tabular}

دريافتند كه دوزهاى مختلف سيكلوفسفاميد مى تواند

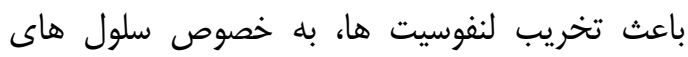

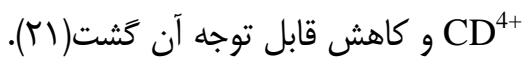
و همين طور در اين مطالعه به اين نتيجه رسيديم

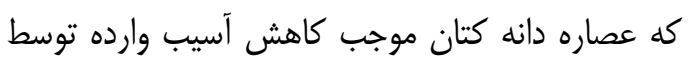

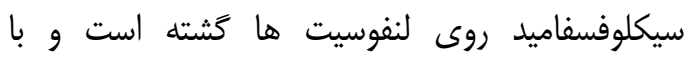
افزايش غلظت عصاره دانه كتان اثرات محافظتى آن در برابر سيكلوفسفاميد بيشتر شد. بنا بر اين عصاره

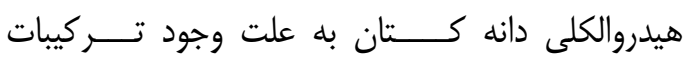
آنتى اكسيدانى مانند تركيبات فنلى و فلاونــــــــيدها

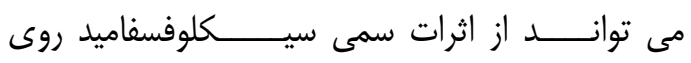

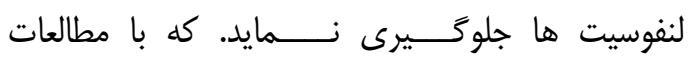
Bhathena كه طى مطالعات بالينى بر روى موش و ديخر حيوانات

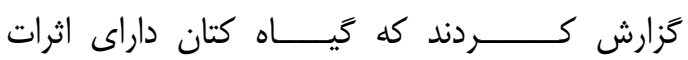

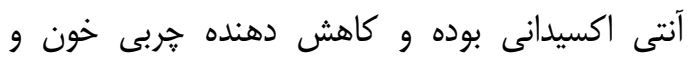

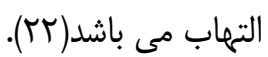

طى آزمايشاتى كه انجام داديم متوجه شديم كتان با دوز MM + +ه داراى اثر محافظتى بالاترى در برابر سيكلوفسفاميد است. بنا بر اين مى توانيم از عصاره

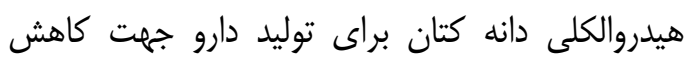

\section{بحث و نتيجه تَيرى}

در سال هاى اخيــــر، روش MN assay يكى از

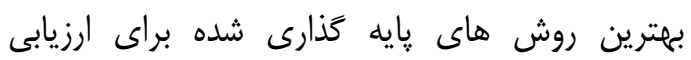
سيتوزنيك ناشى از مواد شيميايى و تابش ها مانى مورد

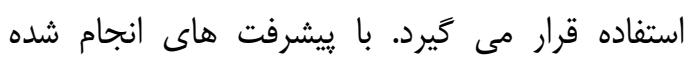
توسط Fenech و Morley، اين روش ارزيابى، بسيار حساس، ساده و سريع براى تشخيص عوامل القاكننده آسيب كروموزومى است(IV) سيكلوفسفاميد يك داروى ضد سرطان است كه در

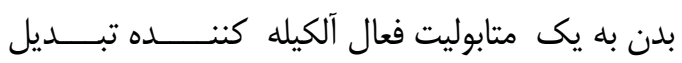
مى كردد(19). اثرات آنتى نئويلاستيكى سيكلوفسفاميد

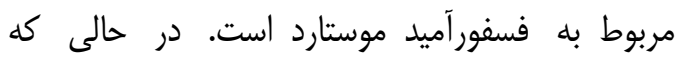
آكرولين از طريق تداخل با سيستم دفاع آنتى اكسيدانى دونى

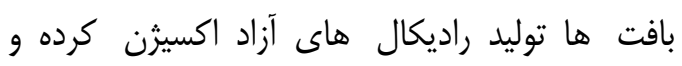
مسئول پييدايش اثرات سمى مانند آيويتوز، تشكيل تومورهاى گوناگون و نكروز مى باشد(

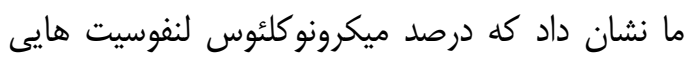
كه تحت سيكلوفسفاميد(كنترل مثبت) قرار كرفتند به ديه

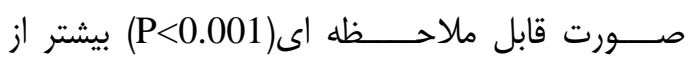

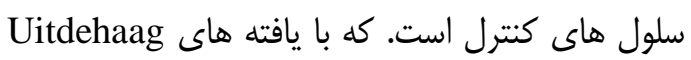
و همكاران در سال 1919 هم خوانى دارد، آن ها يأن هائ 


$$
\text { با دارد با روش هايى اين اثرات مخرب را كاهش دهيم و }
$$$$
\text { باشد. }
$$

\section{References}

1. Ahmadi A, Hosseinimehr SJ, Naghshvar F, Hajir E, Ghahremani M. Chemoprotective effects of hesperidin against genotoxicity induced by cyclophosphamide in Mice bone marrow cells. Arch Pharm Res2008;31:794-7. doi.org/10.1007/s12272-001-1228-z

2. Tiwari AK. Imbalance in antioxidant defence and human diseases: Multiple approach of natural antioxidants therapy. Curr Sci 2001:1179-87. doi.org/10.1016/j.cca.2014.06.004

3. Rehman MU, Tahir M, Ali F, Qamar W, Lateef A, Khan R, et al. Cyclophosphamide-induced nephrotoxicity genotoxicity and damage in kidney genomic DNA of Swiss albino Mice the protective effect of Ellagic acid. Mole Cell Biochem 2012;365:119-27. doi.org/10.1007/s11010-012-1250-x

4. Hales BF. Comparison of the mutagenicity and teratogenicity of cyclophosphamide and its active metabolites 4-hydroxycyclophosphamide phosphoramide mustard and acrolein. Cancer Res 1982;42:3016-21.doi.org/ 00085472/82/0042-OOOOS02.00

5. Nafees S, Ahmad ST, Arjumand W, Rashid S, Ali N, Sultana S. Modulatory effects of gentisic acid against genotoxicity and hepatotoxicity induced by cyclophosphamide in Swiss albino Mice. J Pharm Pharmacol2012;64:259-67. doi.org/10.1111/j.2042-7158.2011.01393.x 6. Hadipour A, Azizi M, Naghdi Badi H, Panahandeh J, Delazar A, Aroei $H$. Phytochemical diversity of Eremostachys laciniata bunge populations in Iran. J Med Plants 2016;1:9-18.

7. Blokhina O, Virolainen E, Fagerstedt KV. Antioxidants oxidative damage and oxygen deprivation stress a review. Annal Botan

:179-94. doi.org/10.1093/aob/mcf118

2003;91

8. Seyoum A, Asres K, Fiky FK. Structure radical scavenging activity relationships of flavonoids. Phytochemistry 2006;67:2058-

$$
\begin{aligned}
& \text { اثرات سمى داروى سيكلوفسفاميد استفاده كنيه. از } \\
& \text { أنجايى كه داروى سيكلوفسفاميد اثرات زنوتاكسيسيته } \\
& \text { بر روى اندام هاى مختلف بدن دارد و به علاوه اين كه }
\end{aligned}
$$

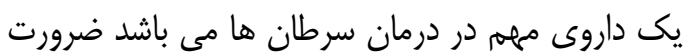

70. doi.org/10.1016/j.phytochem.2006.07.002 9. Yang B, Kotani A, Arai K, Kusu F. Estimation of the antioxidant activities of Flavonoids from their oxidation potentials. Analyt Sci 2001;17:599-604. doi.org/10.2116/analsci.17.599

10. Alfermann AW, Petersen M. Natural product formation by plant cell biotechnology. Plant Cell Tissue Org Cul1995;43:199-205.

doi.org/10.1007/BF00052176

11. Zenk MH, El-Shagi H, Arens H, Stöckigt J, Weiler EW, Deus B. Formation of the indole alkaloids serpentine and ajmalicine in cell suspension cultures of Catharanthus roseus. Springer Berlin Heidel1977; 2:27-43 doi.org/10.1007/9783-642-66646-9_3

12. Lewis JE, Nickell LA, Thompson LU, Szalai JP, Kiss A, Hilditch JR. A randomized controlled trial of the effect of dietary soy and flaxseed muffins on quality of life and hot flashes during menopause. Menopause 2006;13:631-42. doi.org/10.1097/01.gme.0000191882.59799 .67

13. Prasad K. Oxidative stress as a mechanism of diabetes in diabetic BB prone rats: effect of secoisolariciresinol diglucoside. Mole a Cell Biochem 2000;209:89-96.

doi.org/10.1023/A:1007079802459

14. Thompson LU, Ward WE. Flaxseed lignans: health benefits, bioavailability, and safety. Phytoestrogens and health. 2002 Jun 30:405-26. doi:10.3390/ph12020068

15. Rahmati M, Shokrzadeh M, Darabi NK, Modanloo M, Fallah M, Mohammadpour A. The genoprotective effect of Naringin by mifepristone on human blood lymphocyte. Int Pharm Acta2017;1:150-1. doi.org/10.22037/ipa.v1i1.20497

16. Ayoola GA, Coker HA, Adesegun SA, Adepoju AA, Obaweya K, Ezennia EC, Atangbayila TO. Phytochemical screening and antioxidant activities of some selected 
medicinal plants used for malaria therapy in Southwestern Nigeria. Trop J Pharmaceut Res 2008;7:1019-24.

doi.org/10.4314/tjpr.v7i3.14686

17. Fenech M, Morley AA. Measurement of micronuclei in lymphocytes. Mut Res Environ Relate 1985 1;147:29-36. doi.org/10.1016/0165-1161(85)90015-9

18. Shokrzadeh M, Ahangar N, Abdollahi M, Shadboorestan A, Omidi M, Payam SH. Potential chemoprotective effects of selenium on diazinon induced DNA damage in Rat peripheral blood lymphocyte. Hum Exp Toxicol 2013;32:759-65.

doi.org/10.1177/0960327112468179

19. Janelsins MC, Heckler CE, Thompson BD, Gross RA, Opanashuk LA, Slechta DA. A clinically relevant dose of cyclophosphamide chemotherapy impairs memory performance on the delayed spatial alternation task that is sustained over time as mice age. Neurotoxicology 2016;56:28793. doi.org/10.1016/j.neuro.2016.06.013
20. Hill BT, Rybicki L, Carlstrom KD, Jagadeesh D, Gerds A, Hamilton B, et al. Daily weight based busulfan with cyclophosphamide and etoposide produces comparable outcomes to four times daily busulfan dosing for lymphoma patients undergoing autologous stem cell transplantation. Biol Blood Marrow Transplan2016; 22:1588-95.

doi.org/10.1016/j.bbmt.2016.06.011

21. Uitdehaag BM, Nillesen WM, Hommes OR. Long lasting effects of cyclophosphamide on lymphocytes in peripheral blood and spinal fluid. Acta Neurol Scand1989;79:7-12. doi.org/10.1111/j.16000404.1989.tb03702.x

22. Bhathena SJ, Ali AA, Mohamed AI, Hansen CT, Velasquez MT. Differential effects of dietary flaxseed protein and soy protein on plasma triglyceride and uric acid levels in animal models. $\mathbf{J}$ Nut Biochem2002Nov1;13:684-9. doi.org/10.1016/S0955-2863(02)00227-9 


\title{
Effects of Flaxseed (Linum Usitatissimum L.) against Genotoxicity Induced by Cyclophosphamide on Human Blood Lymphocyte
}

\author{
Shokrzadeh $M^{1}$, Mohammadpour $A^{1}$, Modanloo $M^{1}$, Kargardarai $N^{2}$, Khajavi $F^{2 *}$
}

(Received: August 19, 2017

Accepted: April 10, 2019)

\begin{abstract}
Introduction: Medicinal plants, such as flaxseeds play an important role in the health of individuals and communities. Regarding the phytochemical properties of flaxseed, this study aimed to investigate the hydroalcoholic effects of this plant on the genetic toxicity of cyclophosphamide in peripheral blood lymphocytes.
\end{abstract}

Materials \& Methods: The flaxseed extract was initially prepared by maceration using ethanol solvent in two rounds. After one hour of incubation with different concentrations, the blood samples were incubated with $750 \mu \mathrm{M}$ in a bain-marie at $37^{\circ} \mathrm{C}$ for $24 \mathrm{~h}$. To evaluate the production of micronucleus in dual nuclear lymphocytes suppressed in cytokines, the slides were prepared and evaluated using light microscopy. The data were analyzed in SPSS software and the mean values were compared using Tukey's test and.

\section{Ethics code: 30.96 .3 .1002}

Findings: The incubation of blood samples with cyclophosphamide leads to induced additional genotoxicity in lymphocytes. Moreover, flaxseed extract pretreatment significantly reduced the micronucleus frequency $(\mathrm{P}<0.0001)$. In addition, the results showed the effective role of flaxseed extract as a protective agent in reducing the genotoxicity of the pesticide cyclophosphamide.

Discussion \& Conclusions: According to the obtained results, flaxseed is a potent antigenotoxic agent against cyclophosphamide-induced DNA damage. Since the flaxseed extract does not have cytotoxic effects, it can be used as a protective agent against the toxic effects of cyclophosphamide.

Keywords: Cyclophosphamide, Flaxseed, Genotoxicity, Human lymphocyte

\footnotetext{
1. Dept of Toxicology and Pharmacology, Faculty of Pharmacy, Mazandaran University of Medical Sciences, Sari, Iran

2. Dept of Genetics, Mazandaran Sana non-Profit institution, Sari, Iran

*Corresponding author Email: faezekhajavi1370@gmail.com
}

\section{Scientific Journal of Ilam University of Medical Sciences}

